\section{Relative Stability of Adrenaline, Noradrenaline and 5-Hydroxytryptamine subjected to Various Simple Treatments}

WHEN the distribution of active materials in vertebrate tissue is being studied, it is necessary to free tissue extracts from substances which interfere with the bioassay of 5-hydroxytryptamine. Garven ${ }^{x}$ has described a method for the destruction of polyphenols by the polyphenol oxidase present in mushroom juice. The juice contains both polyphenol and monophenol oxidase, and her method therefore makes use of the faster inactivation of adrenaline and noradrenaline by polyphenol oxidase than of 5-hydroxytryptamine by monophenol oxidase. The present method depends on the differential stability of 5-hydroxytryptamine, adrenaline and noradrenaline in alkaline solution. tions 50-200 times those which were found to abolish the response of the tissue to the stated amounts of 5 -hydroxytryptamine are completely inactivated by standing for $30-60 \mathrm{~min}$. at $p H \mathrm{H} 11$ without loss of 5-hydroxytryptamine itself. Heating to $98^{\circ} \mathrm{C}$. for 5 min. at $p \mathbf{H} 7.8$ is equally effective. Heating for 1 min. at $98^{\circ} \mathrm{C}$. and $p \mathrm{H} 9 \cdot 6$ leads to a small loss, and at $p H 11$ to a considerable loss of 5-hydroxytryptamine activity. This last result differs from that reported by Pernow ${ }^{3}$.

Human serum to which adrenaline, noradrenaline and 5-hydroxytryptamine had been added was extracted by addition of four volumes of acetone . $^{4}$ When sodium hydroxide was added to the extracts to give a $p \mathbf{H}$ of $10 \cdot 5-11 \cdot 0$ for $30-60$ min., adrenaline and noradrenaline were destroyed whereas 5-hydroxytryptamine was unaffected. Three such experiments

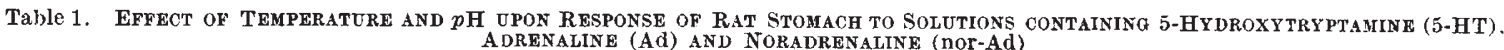

All recoveries as percentage (mean \pm standard error) of response to untreated solutions containing $10 \mathrm{or} 20 \mathrm{~m} \mu \mathrm{gm}$. $/ \mathrm{ml}$ 5-hydroxytryptamine base (5-hydroxytryptamine creatinine sulphate, May and Baker)

Figures in brackets show number of separate experiments performed

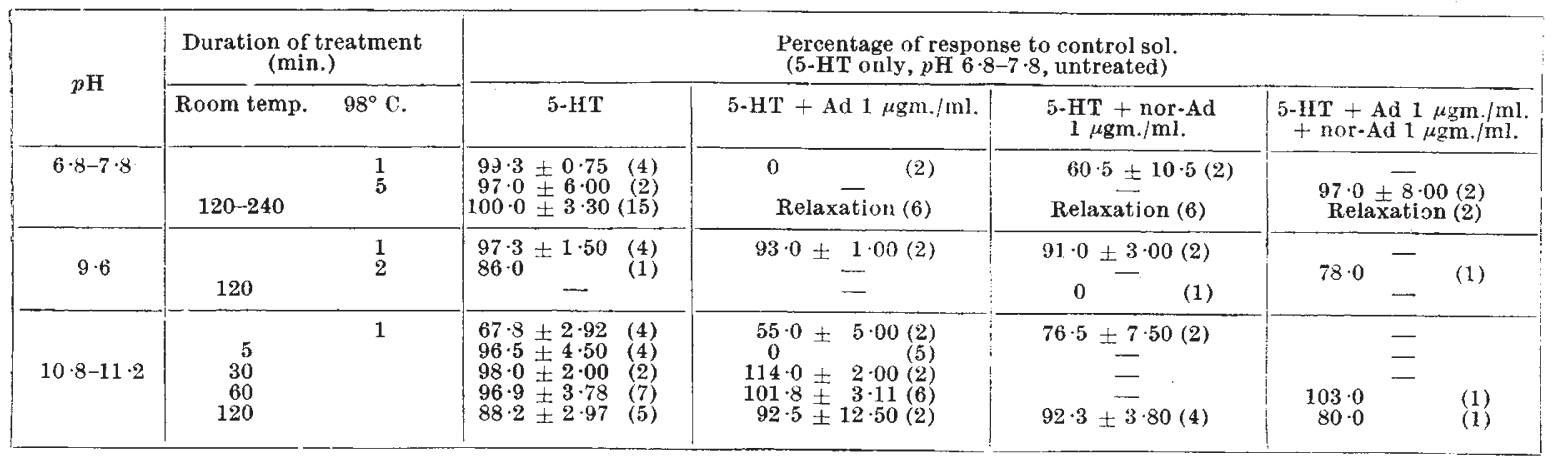

Solutions containing 10 or $20 \mathrm{~m} \mu \mathrm{gm} . / \mathrm{ml}$. 5-hydroxytryptamine were prepared, $\pm 1 \mu \mathrm{gm} . / \mathrm{ml}$. adrenaline and $\pm 1 \mu \mathrm{gm} . / \mathrm{ml}$. noradrenaline, in Tyrode's solution bubbled for $30 \mathrm{~min}$. previously with a gas mixture of 5 per cent carbon dioxide, 95 per cent oxygen. The volume $(0 \cdot 2-0 \cdot 4 \mathrm{ml}$.) of analytical grade sodium hydroxide to give the required $p H$ was added to $25-\mathrm{ml}$. aliquots of solutions in 50-ml. stoppered flasks or test-tubes. The solutions were well mixed by shaking and either left to stand on the bench at room temperature or heated in a water-bath at $98^{\circ} \mathrm{C}$. and then cooled in iced water. Analytical grade hydrochloric acid was added to restore the $p \mathrm{H}$ to neutral, the solutions were well shaken and remained on the bench at room temperature until they were assayed (about $2 \mathrm{hr}$. later). There is no significant loss of activity during this time $(P>0 \cdot 2)$. The $p \mathrm{H}$ of the solutions was checked initially with Johnsons's narrow range indicator papers and in critical experiments by an E.M.I. direct-reading $p \mathrm{H}$ meter.

5-Hydroxytryptamine was assayed upon the rat stomach preparation ${ }^{2}$ in Tyrode's solution at $38^{\circ} \mathrm{C}$. Doses were given according to a 'Latin square' design. In all experiments the test solutions were compared with untreated solutions of 5-hydroxytryptamine to which Tyrode's saline had been added in volumes equal to those of sodium hydroxide and hydrochloric acid. All recoveries are expressed as percentage of response to untreated solutions containing 5-hydroxytryptamine only.

Table 1 summarizes the results of fifteen experiments. Adrenaline and noradrenaline in concentra- gave recoveries of 5-hydroxytryptamine between 92 and 100 per cent of the control value $(96 \cdot 2 \pm 1 \cdot 7)$.

Thus both adrenaline and noradrenaline in a concentration of 50-200 times that of 5-hydroxytryptamine - a ratio which occurs in certain parts of the brain of vertebrates ${ }^{5}$ - are selectively destroyed by treatments which have little or no effect on the concentration of 5-hydroxytryptamine.

\section{DAPHNE JOYCE}

Academic Unit in Neurology,

Institute of Neurology,

Queen Square,

London, W.C.I. June 11.

1 Garven, J. D., Brit. J. Pharmacol., 11, 66 (1956).

${ }^{2}$ Vane, J. R., Brit. J. Pharmacol., 12, 344 (1957)

${ }^{3}$ Pernow, B., Acta physiol. Scand., 29, supp. 105 (1953)

4 Correale, P., J. Neurochem., 1, 22 (1956).

${ }^{5}$ Amin, A. H., Crawford, T. B. B., and Gaddum, J. H., J. Physiol. 126, 596 (1954).

${ }^{6}$ Vogt, M., J. Physiol., 123, 451 (1954).

\section{Application of Direct Photographic Photometry to Preparative Electrophoresis}

THE supporting medium of most preparative methods of electrophoresis includes a solidified gel or porous solid in order to reduce thermal convection ${ }^{1}$. A buffer stabilized in the form of a clear solution, without a solid support, would have the advantages of avoiding adsorption effects between the migrating 